Faculty of Science

Faculty Publications

This is a post-review version of the following article:

A Study of Methanol Oxidation by Dynamic Electrochemical Impedance Spectroscopy

Per K. Dahlstrom, D. A. Harrington and F. Seland

2012

The final published version of this article can be found at:

http://dx.doi.org/10.1149/1.3695100

Citation for this paper:

Dahlstro/m, P.K., Harrington, D.A. \& Seland, F. (2012). A Study of Methanol Oxidation by Dynamic Electrochemical Impedance Spectroscopy. ECS Transactions, 41(21), 35-47. http://dx.doi.org/10.1149/1.3695100 
Accepted version of ECS Transactions 41 (2012) 35-47. doi: 10.1149/1.3695100

(C) The Electrochemical Society, Inc. 2012. All rights reserved. Except as provided under U.S. copyright law, this work may not be reproduced, resold, distributed, or modified without the express permission of The Electrochemical Society (ECS).

\title{
A Study of Methanol Oxidation by Dynamic Electrochemical Impedance Spectroscopy
}

\author{
P. K. Dahlstrøm ${ }^{\mathrm{a}}$, D. A. Harrington ${ }^{\mathrm{b}}$, and F. Seland ${ }^{\mathrm{a}}$ \\ ${ }^{a}$ Department of Materials Science and Engineering, Norwegian University of Science and \\ Technology, 7491 Trondheim, Norway \\ ${ }^{\mathrm{b}}$ Chemistry Department, University of Victoria, Victoria B.C. V8W 3V6, Canada
}

\begin{abstract}
Methanol oxidation on a smooth polycrystalline platinum electrode is studied by dynamic electrochemical impedance spectroscopy at elevated temperatures employing an autoclave setup. By utilizing custom written software, impedance spectra for all applied electrode potentials are calculated. By increasing the temperature and/or sweep rate, it is shown that the region with three adsorbed species disappears, which is interpreted as less contribution of the parallel pathway at higher temperatures.
\end{abstract}

\section{Introduction}

A direct methanol fuel cell (DMFC) uses oxidation of methanol as an anode reaction, which has advantages over hydrogen gas in connection with storage and handling and has received a lot of attention in the literature. The oxidation process is now commonly accepted to proceed through two pathways, one that involves a strongly adsorbed intermediate species, $\mathrm{CO}$ (ads), which dominates at Pt surfaces at ambient conditions, and a parallel path through short-lived, weakly adsorbed, intermediates to stable oxidation products like formaldehyde, formic acid and $\mathrm{CO}_{2}$. The electrooxidation of methanol has been reviewed recently (1-5).

The kinetics of the methanol oxidation reaction is rather slow at ambient conditions due to the severe poisoning of active $\mathrm{Pt}$ sites with $\mathrm{CO}(\mathrm{ads})$ species formed during the oxidation process. One way to enhance the removal of the strongly adsorbed species, is to use a catalyst modifier like ruthenium, that shifts the onset potential for $\mathrm{CO}$ oxidation to more negative potentials by more readily supplying the necessary oxygen donating species. This has become known as the bifunctional mechanism. The rate can also be increased by increasing the temperature, which greatly enhances electrode kinetics.

A DMFC is normally operated between $60-130{ }^{\circ} \mathrm{C}(6)$, as constrained by the membrane material used. Wang and Baltruschat (7) studied the effect of various parameters like anion, temperature and surface structure on methanol oxidation at Pt electrodes by DEMS, and found that they did not alter the current efficiency of $\mathrm{CO}_{2}$. However, they used an open cell and were limited to $50{ }^{\circ} \mathrm{C}$ to avoid any time effects due to loss of methanol from the electrolyte as a consequence of the low boiling point of methanol, $65^{\circ} \mathrm{C}$. Kardash and Korzeniewski (8) reported, in an IR study of methanol oxidation on polycrystalline platinum up to $70{ }^{\circ} \mathrm{C}$, that the amount of detectable adsorbed $\mathrm{CO}$ decreases, and the rate of $\mathrm{CO}_{2}$ 
formation increases with increasing temperature. Chojak-Halseid et al. (9) used a high temperature/high pressure thin-layer channel flow cell combined with differential electrochemical mass spectrometry to study methanol oxidation on a $\mathrm{Pt} / \mathrm{C}$ catalyst at $23-100{ }^{\circ} \mathrm{C}$ and up to 3 bar overpressure. They found that the apparent activation energies for $\mathrm{CO}_{2}$ formation were generally larger than those for the overall reaction, suggesting an increased selectivity towards $\mathrm{CO}_{2}$ with temperature. In fact, they report a complete converstion to $\mathrm{CO}_{2}$ at about $100{ }^{\circ} \mathrm{C}(10)$. Clearly, a change of the relative rates of the various reaction paths occur with temperature, readily allowing for the complete oxidation to $\mathrm{CO}_{2}$.

Among the methanol oxidation studies at elevated temperatures found in the literature, electrochemical impedance spectroscopy (EIS) has been rarely used, and only a few papers are found for room temperature studies. Otomo et al. (11) studied oxidation of 2propanol and methanol on carbon-supported Pt catalysts with EIS in the temperature range of $303-353 \mathrm{~K}$. Lee et al. (12) showed the existence of a Hopf bifurcation in methanol oxidation on platinum. Melnick and Palmore (13) and Hsing et al. (14) utilized EIS as a tool to study the methanol oxidation mechanism and discussed their data in terms of single-adsorbate and two-adsorbate models.

Previously we studied methanol oxidation at a Pt electrode by an a.c. voltammetry method at room temperature, where a negative relaxation time constant was attributed to nucleation and growth behaviour (15). In this work we employ a similar dynamic electrochemical impedance spectroscopy (dEIS) method, but now with simultaneous collection of impedance values for a range of frequencies (16), and study methanol oxidation on smooth polycrystalline platinum electrodes in an autoclave setup operating with temperatures ranging from room temperature to $100{ }^{\circ} \mathrm{C}$. With this method impedance data is collected "on the fly", enabling the study of non-steady-state conditions at the surface, such as partially covered surfaces. Furthermore, the experiments are carried out in a sealed and pressurized three-electrode system allowing for operation up to, and beyond, $100{ }^{\circ} \mathrm{C}$ and thus avoiding the complexity introduced by employing a real fuel cell with nanoparticle catalysts and oxygen electrode. Various ways to increase the temperature during the study of methanol oxidation have been employed by a number of groups, $(8,9,17-22)$.

Variations in the impedance behaviour as a function of sweep rate and temperature are given and analysed in terms of equivalent circuits and mechanisms. Regions of hidden negative differential resistance are identified at low sweep rates and low temperatures, suggesting existence of bifurcations in the methanol oxidation process. The existence of bifurcations and electrochemical oscillating systems have been reported previously in the literature (e.g. (12)), but only sparse information is given on the instability in the methanol oxidation at Pt electrodes $(12,23)$.

\section{Experimental}

A normal three-electrode setup inside an autoclave (miniclave from Büchi Glas Uster AG) was used. The working electrode was a platinum sheet of approximately $3 \mathrm{~cm}^{2}$, the counter electrode was a platinum mesh, and a reversible hydrogen electrode (RHE) immersed in the same electrolyte inside the autoclave unit was used as the reference electrode. All potentials 
given in this work are reported vs this reference (RHE). Before each experimental sequence, the autoclave glass cell and all other glass equipment were cleaned by overnight immersion in hot concentrated sulphuric acid followed by thoroughly rinsing in Milli-Q water. All current densities are normalized with respect to the true electrochemical surface area by assuming that the charge under the voltammetric hydrogen adsorption peaks corresponds to $220 \mu \mathrm{C} \mathrm{cm}{ }^{-2}$.

For all experiments, sulphuric acid (Acros organics, 99.8\%), diluted by Milli-Q water to $0.5 \mathrm{M}$, was used as the base electrolyte. Oxygen was removed from the solution by bubbling Ar for one hour prior to sealing and heating of the autoclave to the desired temperature. The platinum working electrode was cycled at $100 \mathrm{mV} \mathrm{s}^{-1}$ for 1 hour, followed by characterization with cyclic voltammetry at different sweep rates, potentiostatic electrochemical impedance at every $50 \mathrm{mV}$ between 0.30 and $1.55 \mathrm{~V}$ and dynamic electrochemical impedance spectroscopy (dEIS) with sweep rates of 1,5 , and $10 \mathrm{mV} \mathrm{s}^{-1}$. At this point, methanol (Merck, suprapur) was added to obtain a concentration of $1.0 \mathrm{M}$ and the whole experimental sequence was repeated.

In dEIS, a multi-sine potential wave is applied on top of a slow d.c. potential scan. In this case, the multi-sine wave contained 46 sine waves with different frequency, amplitude and phase. A thorough description of the system including limitations for the frequency range and d.c. sweep rate is given in (16). The frequency ranges applied during the dEISmeasurements were $0.2 \mathrm{~Hz}-2.6 \mathrm{kHz}$ for $1 \mathrm{mV} \mathrm{s}^{-1}$ and $2 \mathrm{~Hz}-26 \mathrm{kHz}$ for 5 and $10 \mathrm{mV} \mathrm{s}^{-1}$. Custom made software was employed to calculate the real and imaginary impedance values for all applied frequencies by performing a fast fourier transform algorithm on the dEIS raw data. Impedance spectra for all potentials swept over can be extracted. In this work, impedance spectra at every $2 \mathrm{mV}$ around the voltammogram were extracted. These impedance spectra were fitted to selected equivalent circuits with the software ZSimpWin 3.20 (Echem Software, http://www.echemsw.com) using modulus weighting. Elements were added to the equivalent circuit when justified with the F-ratio test of adding an element $(15,24)$.

\section{Results}

d.c. voltammetry

Cyclic voltmmograms for platinum in sulphuric acid as a function of temperature are given in Fig. 1(a). The voltammograms clearly demonstrate that the onset potential for formation of platinum oxide is shifted to more negative potentials with increasing temperatures and that there is a steeper current rise once the formation starts. This has been explained in terms of an increased water activity at the surface with increased temperature (25). Furthermore, as the temperature increases the kinetics for the oxygen evolution reaction is also improved resulting in a more pronounced current increase at the high potential end of the voltammograms. Upon reversing the potential scan the platinum reduction peak becomes steeper and higher with increased temperature, again as a result of increased reaction rates, with only a small shift of the reduction peak to more positive potentials. 


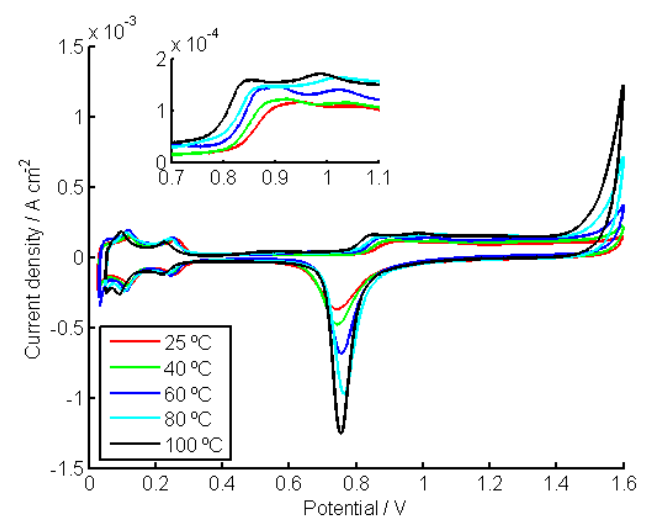

(a)
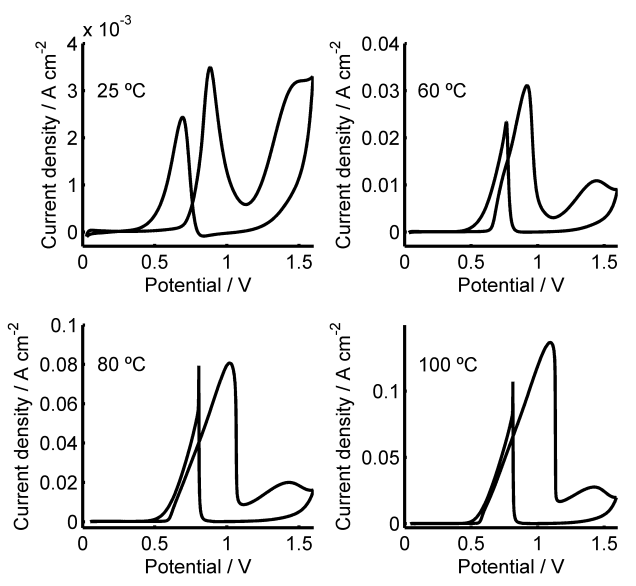

(b)

Figure 1. Cyclic voltammograms as a function of temperature for (a) sulphuric acid solution and (b) $1.0 \mathrm{M}$ methanol in sulphuric acid. Sweep rate, $100 \mathrm{mV} \mathrm{s}^{-1}$ at a smooth Pt electrode. The inset in (a) shows a magnification of the potential range with the onset of platinum oxide formation.

Fig. 1(b) represents the corresponding voltammograms at the Pt electrode after addition of $1.0 \mathrm{M}$ methanol to the sulphuric acid electrolyte at a sweep rate of $100 \mathrm{mV} \mathrm{s}^{-1}$. In the low potential region, below approximately $0.6 \mathrm{~V}$, the current is close to zero due to blocking by adsorbed $\mathrm{CO}$ formed through dehydrogenation of methanol. Above this potential (around $0.5-0.6 \mathrm{~V}$, depending on temperature), some stripping of the adsorbed $\mathrm{CO}$ occur, which allows for further methanol dehydrogenation, and the current near the onset potential increases. The current peak is shifted to more positive potentials with an increase in temperature, from around $0.89 \mathrm{~V}$ at $25{ }^{\circ} \mathrm{C}$ to $1.09 \mathrm{~V}$ at $100{ }^{\circ} \mathrm{C}$. As the temperature increases, the onset potential for methanol oxidation is shifted to more negative, and favourable potentials, while the current density is significantly increased due to improved electrode kinetics. Furthermore, the current decline at the positive potential side of the oxidation peak becomes steeper due to the more readily formation of oxide at higher temperatures.

Another oxidation peak appears at the high potential end of the voltammograms (around $1.4 \mathrm{~V}$ ) perhaps due to a change in the oxide structure so that it is more active towards methanol adsorption and oxidation. With increasing temperature, the peak shifts slightly towards more negative potentials.

On the reverse scan the current density quickly goes towards zero and stays there until a sharp positive increase occurs at about $0.75 \mathrm{~V}$, coinciding with the onset of platinum oxide reduction. An oxidation peak follows at slightly more negative potentials due to formation of $\mathrm{CO}$ (ads) which blocks the surface as the potential decreases. The necessity of reducing the platinum oxide is clearly visible in the voltammogram for $25^{\circ} \mathrm{C}$, where the current density becomes slightly negative before the onset of the oxidation peak. As the temperature increases, the peaks become steeper again due to improved kinetics, leading to more rapid oxide reduction and subsequent methanol adsorption and oxidation at the freshly produced Pt sites. 


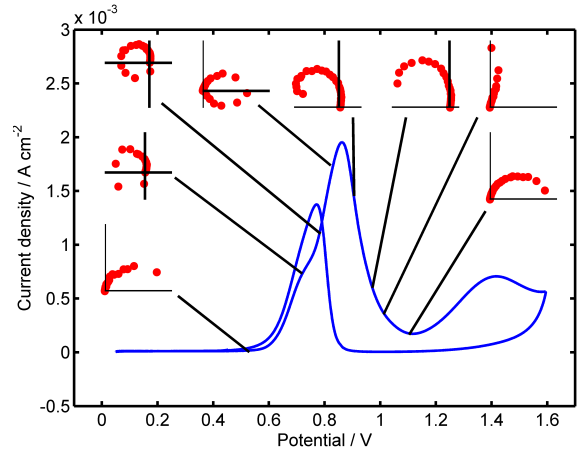

(a)

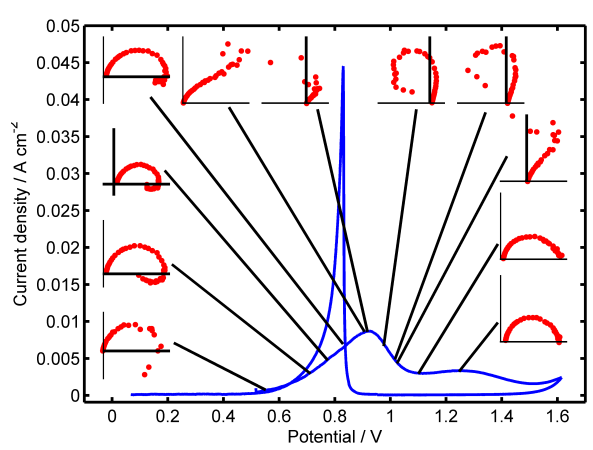

(b)

Figure 2. Cyclic voltammogram and impedance spectra from the dEIS measurements. The sweep rate was $1 \mathrm{mVs}^{-1}$ and temperature was a) $25{ }^{\circ} \mathrm{C}$ and b) $80^{\circ} \mathrm{C}$.

\section{dEIS spectra}

Fig. 2 gives a schematic representation of the impedance spectra obtained with the dEIS technique during the positive going scan along with the cyclic voltammograms directly extracted from the raw data recorded during the dEIS measurements. The impedance spectra therefore directly measure the surface condition at any potential given in the voltammogram, without any shifts due to slow system changes over time, as experienced previously with a.c. voltammetry $(15,26)$. Time effects in EIS were studied in more details by Melnick and Palmore (13). At potentials in the double-layer region, at approximately $0.40-0.61 \mathrm{~V}$ in the positive-going sweep, and $25^{\circ} \mathrm{C}$, the Nyquist plots show only signs of one semicircle in the first quadrant. These spectra are therefore best fitted to a parallel combination of the double-layer capacitance and the charge-transfer resistance in series with the electrolyte resistance, circuit $\mathrm{R}$ in Fig. 3. As usual, a constant phase element was used in the fitting to represent the double layer capacitance, and was justified by a simple statistical F-test. As the current increases, and during the rising part of the lower side of the peak $(0.61-0.69 \mathrm{~V})$, below the observed shoulder at about $0.70 \mathrm{~V}$, the spectra flip backwards into the second quadrant. Now an extra relaxation is needed in the equivalent circuit model in order to appropriately fit the data (given that the charge transfer resistance is always positive). Circuit L in Fig. 3 was chosen in this potential region even though a capacitance is preferred from a physical point of view. Employing circuit L, with an inductor, proved to make the fitting converge more easily, as also found previously (15)). Later in the peak, between the shoulder and the maximum $0.70-0.85 \mathrm{~V}$, the spectra continuosly evolve: they first cross the real axis on the negative side and enter into both the third and fourth quadrants, and then suddenly flip over and go through the first and fourth quadrants only. In this entire potential region, the spectra end up on the positive side of the real axis as $\omega \rightarrow 0$. An equivalent circuit with two relaxations, in addition to the double-layer/charge-transferrelaxation, is required to satisfactorily fit the data between $0.70-0.80 \mathrm{~V}$. Circuit $2 \mathrm{~L}$ in Fig. 3 is used here. Between $0.8 \mathrm{~V}$ and $0.85 \mathrm{~V}$, just before the current peak, the Nyquist spectra briefly enter the fourth quadrant, and were best fitted with circuit $\mathrm{L}$ with a positive R1 and L1. At the peak, the impedance becomes very large before flipping back into the second quadrant. In this region, the circuit L again produces the best fit, with both R1 and 
$\mathrm{L} 1$ negative. For a short potential region after the peak, $0.86-0,87 \mathrm{~V}$, circuit $2 \mathrm{~L}$ gives the best fit before circuit $\mathrm{L}$ again gives the best fit. Close to the current minimum near $1 \mathrm{~V}$, the Nyquist spectra flip back into the first quadrant again, displaying a partial semi-circle, and remains like this for the rest of the positive going scan. An overview of the chosen equivalent circuits as justified by a statistical F-test for the various potential regions are given in Table I, together with the sign of the fitted parameters R1, L1, R2, and L2.

Effect of temperature and sweep rate. The right side of Fig. 2 gives a qualitative overview of the impedance spectra observed at $80^{\circ} \mathrm{C}$. At first glance, the impedance behaviour follows the same trend as for $25^{\circ} \mathrm{C}$, but with one clear exception. There is no potential region in the rising part of the current peak where the impedance spectra cross into the second quadrant. However, fourth quadrant classical inductive behaviour was found, and fitting to circuit $\mathrm{L}$ found only positive fitting parameters in this potential region. The real part of impedance is always positive in this region. Furthermore, the equivalent circuit $2 \mathrm{~L}$ is not needed during fitting of the impedance data at $80{ }^{\circ} \mathrm{C}$. An overview of the fitting results is given in Table II.

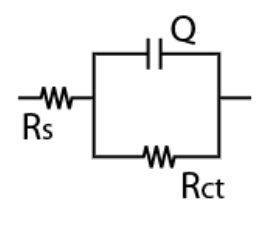

$\mathrm{R}$

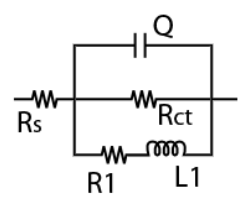

$\mathrm{L}$

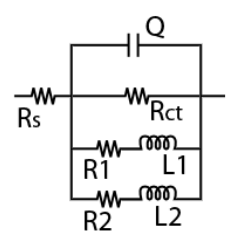

$2 \mathrm{~L}$

Figure 3. Equivalent circuits to fit the experimental impedance data.

The hidden negative resistance disappears when the temperature is between $60{ }^{\circ} \mathrm{C}$ and $80{ }^{\circ} \mathrm{C}$, see Fig. 4(a). At temperatures lower than $80^{\circ} \mathrm{C}$, the impedance spectra form a counter-clockwise circle, by crossing the negative real axis. Again, the equivalent circuit $2 \mathrm{~L}$ is necessary to obtain acceptable fits in this potential region, $0.70-0.80 \mathrm{~V}$. When increasing the temperature to $80^{\circ} \mathrm{C}$ and higher, the impedance spectra remains in the first and fourth quadrant and the simpler circuit, L, can be used to fit the experimental results. Increasing the temperature to $100{ }^{\circ} \mathrm{C}$ mimics the shape of the spectra at $80{ }^{\circ} \mathrm{C}$, but reduces their size, suggesting a lowering of the charge transfer resistance, but without alteration of the oxidation mechanism.

The right side of Fig. 4(b) gives the sweep rate dependence of the impedance spectra at $25^{\circ} \mathrm{C}$ and $0.70 \mathrm{~V}$. Clearly, the impedance spectrum changes from being a partial semicircle in the first quadrant at 5 and $10 \mathrm{mV} \mathrm{s}^{-1}$ to almost a full counter-clockwise circle both at $1 \mathrm{mV} \mathrm{s}^{-1}$ and for potentiostatic EIS. 

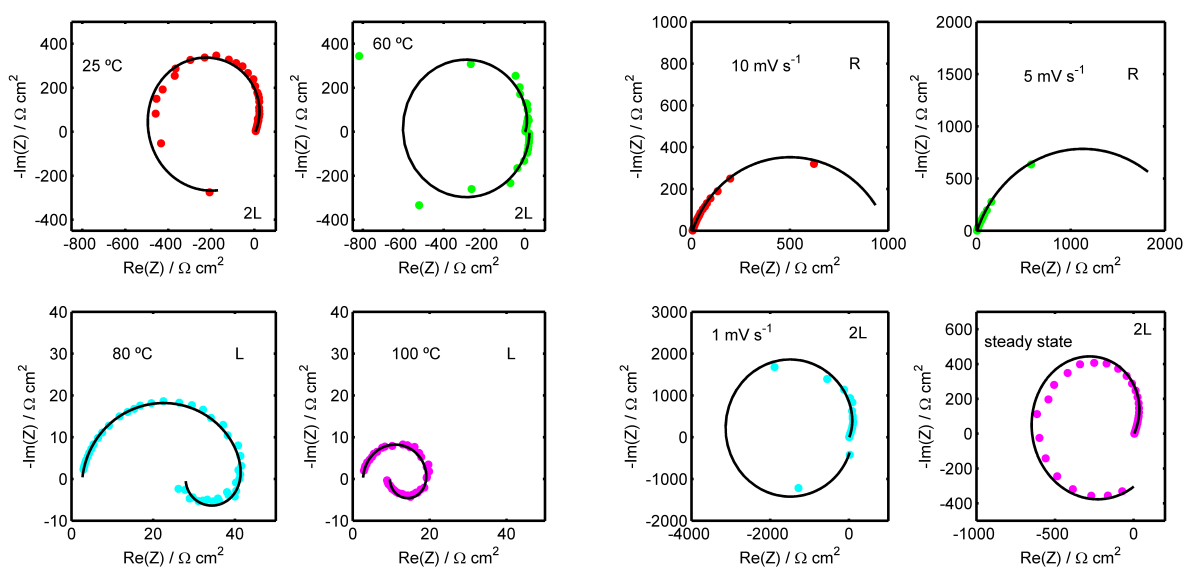

(a)

(b)

Figure 4. Impedance spectra as a function of (a) temperature $\left(25,60,80\right.$, and $\left.100{ }^{\circ} \mathrm{C}\right)$ at $0.73 \mathrm{~V}$ and $1 \mathrm{mV} \mathrm{s}^{-1}$ and (b) sweep rate $\left(10,5,1 \mathrm{mV} \mathrm{s}^{-1}\right.$ and steady state) at $0.70 \mathrm{~V}$ and $25{ }^{\circ} \mathrm{C}$. Circles are experimental values and the lines represent the best fits to the appropriate equivalent circuit indicated in each plot.

TABLE I. Equivalent circuits used in the different potential regions and the sign of the fitted parameters at $25^{\circ} \mathrm{C}$.

\begin{tabular}{cccccc}
\hline Potential (V) & Circuit & R1 & L1 & R2 & L2 \\
\hline$<0.610$ & $\mathrm{R}$ & $\mathrm{n} / \mathrm{a}$ & $\mathrm{n} / \mathrm{a}$ & $\mathrm{n} / \mathrm{a}$ & $\mathrm{n} / \mathrm{a}$ \\
$0.610-0.690$ & $\mathrm{~L}$ & + & + & $\mathrm{n} / \mathrm{a}$ & $\mathrm{n} / \mathrm{a}$ \\
$0.700-0.800$ & $2 \mathrm{~L}$ & - & + & + & + \\
$0.810-0.850$ & $\mathrm{~L}$ & + & + & $\mathrm{n} / \mathrm{a}$ & $\mathrm{n} / \mathrm{a}$ \\
$0.860-0.870$ & $2 \mathrm{~L}$ & - & - & + & + \\
$0.880-1.050$ & $\mathrm{~L}$ & - & - & $\mathrm{n} / \mathrm{a}$ & $\mathrm{n} / \mathrm{a}$ \\
$1.060-1.600$ & $\mathrm{R}$ & $\mathrm{n} / \mathrm{a}$ & $\mathrm{n} / \mathrm{a}$ & $\mathrm{n} / \mathrm{a}$ & $\mathrm{n} / \mathrm{a}$ \\
\hline
\end{tabular}

TABLE II. Equivalent circuits used in the different potential regions and the sign of the fitted parameters at $80{ }^{\circ} \mathrm{C}$.

\begin{tabular}{cccc}
\hline Potential (V) & Circuit & R1 & L1 \\
\hline$<0.566$ & $\mathrm{R}$ & $\mathrm{n} / \mathrm{a}$ & $\mathrm{n} / \mathrm{a}$ \\
$0.566-0.886$ & $\mathrm{~L}$ & + & + \\
$0.896-1.075$ & $\mathrm{~L}$ & - & - \\
$1.075-1.600$ & $\mathrm{R}$ & $\mathrm{n} / \mathrm{a}$ & $\mathrm{n} / \mathrm{a}$ \\
\hline
\end{tabular}




\section{Discussion}

\section{$\underline{\text { Mechanistic considerations }}$}

As described in the previous section, increasing the temperature lowers the onset potential for methanol oxidation in the positive-going scan, likely due to an increased activity of water at the surface, which enables $\mathrm{CO}(\mathrm{ads})$ stripping at more negative potentials. Furthermore, the main methanol oxidation peak shifts slightly to more positive potentials with temperature. Before giving any arguments for the latter, some considerations concerning the nature of the current peak itself are given. This can be rationalized in terms of a simplified reaction scheme, assuming that the coverages of the adsorbed species always add to one, and that the reaction kinetics is proportional to the product of the coverages.

$$
\begin{gathered}
\mathrm{Pt}+\mathrm{CH}_{3} \mathrm{OH}(\mathrm{aq}) \rightarrow \mathrm{CO}(\text { ads })+4 \mathrm{H}^{+}+4 \mathrm{e}^{-} \\
\mathrm{Pt}+\mathrm{H}_{2} \mathrm{O} \rightarrow \mathrm{OH}(\text { ads })+\mathrm{H}^{+}+\mathrm{e}^{-} \\
\mathrm{CO}(\text { ads })+\mathrm{OH}(\text { ads }) \rightarrow \mathrm{CO}_{2}+\mathrm{H}^{+}+\mathrm{e}^{-}+2 \mathrm{Pt}
\end{gathered}
$$

As a starting point, assume that there is no replenishment of methanol, or possibility of readsorption of $\mathrm{CO}(\mathrm{ads})$ at the active sites that are freed in the reaction between adsorbed $\mathrm{CO}$ and $\mathrm{OH}$ (reaction 3), which is also considered as the rate limiting step in the high current region. The current peak thus corresponds to the point where the product of the coverages is a maximum, i.e., when the coverages of $\mathrm{CO}$ (ads) and $\mathrm{OH}(\mathrm{ads})$ are both 0.5 . Once the reaction to form $\mathrm{CO}_{2}$ occurs, the two freed $\mathrm{Pt}$ sites will be occupied with an oxygen source, in this case $\mathrm{OH}(\mathrm{ads})$ as in reaction 2.

However, this is not the case for methanol oxidation with methanol present in the electrolyte, where the active Pt adsorption sites that are freed in the reaction step 3 are rapidly filled with either adsorbed $\mathrm{CO}$ or $\mathrm{OH}$ by reactions 1 and 2 . Furthermore, the fact that methanol requires neighbouring active sites for the dehydrogenation process and that formation of other oxide structures occurs when increasing the potential (e.g. PtO formation according to reaction 4) means that the process cannot really be this simple. In fact, the saturation coverage of $\mathrm{CO}$ residues from methanol oxidation decreases already at potentials around $0.55 \mathrm{~V}$ at room temperature, and is almost absent at the peak potential (27). The reasoning behind the current peak formation in the methanol oxidation is thus the progressive coverage of platinum oxide, which encompass a significantly lower activity towards methanol adsorption and subsequent dehydrogenation as compared to the freed Pt sites from reaction 3 . 


$$
\mathrm{Pt}+\mathrm{H}_{2} \mathrm{O} \rightarrow \mathrm{O}(\mathrm{ads})+2 \mathrm{H}^{+}+2 \mathrm{e}^{-}
$$

Clearly, as seen from Fig. 1(a), the oxide formation rises steeply once it starts, and even more rapidly as well as slightly shifted to more negative potentials with higher temperatures. The rate of methanol adsorption and oxidation also increases with temperature as can be seen by the enhanced current density observed in the voltammograms with increased temperature (Fig. 1(b)). The contradictory increase in peak potential can be explained in terms of a relative increase in the rate of methanol adsorption and dehydrogenation thus effectively delaying the all-embracing formation of platinum oxide to more positive potentials. This temperature effect was seen to be even more pronounced at $\mathrm{Pt} / \mathrm{C}$ catalysts, but not for $\mathrm{PtRu} / \mathrm{C}$ catalysts up to $80{ }^{\circ} \mathrm{C}(28)$.

Evaluation of impedance data

The apparent number of adsorbed species observed in the impedance spectra (one more than the number of relaxation times) reflects the number of independently-adsorbed species existing at the surface. If two species completely fill the surface, the number of kinetically significant species is one. Thus, for circuit L, which represents one adsorption relaxation, two surface species exist, e.g. adsorbed $\mathrm{CO}$ and adsorbed $\mathrm{OH}$, according to reactions 1 and 2.

If the number of surface species increases to three, for example $\mathrm{CO}(\mathrm{ads}), \mathrm{OH}(\mathrm{ads})$ and either free Pt sites or $\mathrm{O}(\mathrm{ads})$, two adsorption relaxations are needed, circuit $2 \mathrm{~L}$, in order to appropriately model the a.c. response. At low temperatures and slow sweep rates, potential regions with two independent adsorbed species exist: 1) a region in the middle of the rising part of the peak and 2) a small region right after the peak potential, in the start of the declining part of the peak. The latter is harder to understand as this is in the oxide region, and will be the subject of further investigation.

According to Melnick and Palmore (13), the parallel pathway can only be studied by impedance spectroscopy if the coverage of the corresponding adsorbed intermediates are significant enough to be detected. If detectable, parallel pathways will be indicated by impedance spectra containing three or more semi-circles. The third surface species present in these results, whether it is free platinum sites or another adsorbed species, may be related to the parallel pathway. Thus, the amount of current related to the parallel pathway seems to decrease with increasing temperature as the signature for three independent species ceases to exist in the impedance spectra. The same was seen for slightly faster d.c. sweeps ( 5 and $10 \mathrm{mV} \mathrm{s}^{-1}$ ), where we previously interpreted a negative time constant as experimental evidence for nucleation and growth behaviour in the methanol oxidation at platinum surfaces (15). In this work we also identify a region with a negative time constant during the positive going sweep between $0.70 \mathrm{~V}$ and $0.80 \mathrm{~V}$ at $25^{\circ} \mathrm{C}$ and $1 \mathrm{mV} \mathrm{s}^{-1}$ in line with the previous work. The region with a negative time constant disappears at higher temperatures.

It is well known that electrochemical instabilities and oscillatory behaviour occur in the 
oxidation of formic acid (29) and how the relative change in coverages change the interfacial potential with respect to the applied potential. De Levie (30) and Koper (31) pointed out the possibility of deducing incipient oscillations from the EIS spectra. More specifically, if the impedance crosses the negative real axis, from third quadrant to fourth quadrant, at a finite frequency, $\omega_{H}$, a Hopf bifurcation is possible. Such a signature is indeed what we see at low sweep rates and low temperatures in the potential region $0.70-0.80 \mathrm{~V}$ suggesting that oscillations can be induced by adding a large enough external resistor to the working electrode circuit, forcing the crossing to be through the origin.

Lee et al. (12) detected a Hopf bifurcation and a hidden negative differential resistance (HNDR) for methanol oxidation on platinum and observed potential oscillations under galvanostatic control. Also Hsing et al. (14), and Melnick and Palmore (13) observed second and third quadrant behaviour in their impedance spectra for methanol oxidation.

Looking closer at the dEIS measurements given in Fig. 4 the negative crossing of the real part of impedance into third quadrant dissappears as the sweep rate is increased (Fig. 4(b)) at room temperature in the potential region $0.70-0.80 \mathrm{~V}$. This perhaps suggests that the slow-sweep impedance ( 5 and $10 \mathrm{mV} \mathrm{s}^{-1}$ ) used here allows access to regions not accessible at true steady state. Similarly, an increase in temperature provides no indications of two adsorption relaxations in any potential regions, and no crossing of the negative real part of impedance is seen. In fact, the impedance always has a positive real part for potentials up to the current peak. During the decreasing side of the voltammetric peak, the impedance shows only second quadrant behaviour and suggests a negative zero limit of the real part of the impedance, as predicted from the negative slope of the voltammogram.

$$
\begin{gathered}
\mathrm{CH}_{3} \mathrm{OH}(\mathrm{aq}) \rightarrow \mathrm{HCHO}+2 \mathrm{H}^{+}+2 \mathrm{e}^{-} \\
\mathrm{CH}_{3} \mathrm{OH}(\mathrm{aq})+\mathrm{H}_{2} \mathrm{O} \rightarrow \mathrm{HCOOH}+4 \mathrm{H}^{+}+4 \mathrm{e}^{-} \\
\mathrm{HCHO}+\mathrm{H}_{2} \mathrm{O} \rightarrow \mathrm{CO}_{2}+4 \mathrm{H}^{+}+4 \mathrm{e}^{-} \\
\mathrm{HCOOH} \rightarrow \mathrm{CO}_{2}+2 \mathrm{H}^{+}+2 \mathrm{e}^{-}
\end{gathered}
$$

Furthermore, Chojak-Halseid et al. (9) reported in their DEMS work an increased selectivity towards $\mathrm{CO}_{2}$ formation at a $\mathrm{Pt} / \mathrm{C}$ catalyst as the temperature is increased from room temperature and up to $100{ }^{\circ} \mathrm{C}$. In fact, they concluded that eventually all methanol is converted to $\mathrm{CO}_{2}$ at $100{ }^{\circ} \mathrm{C}$. Combined with the dEIS results presented here, where there is no indication in the EIS spectra of any parallel reaction paths involving more than one kinetically significant species, i.e., only one adsorption relaxation implying that the surface has only two adsorbed species, $\mathrm{CO}$ (ads) and $\mathrm{OH}(\mathrm{ads})$, or $\mathrm{CO}$ (ads) and $\mathrm{O}$ (ads). This may suggest that the formation of $\mathrm{CO}_{2}$ dominates the reaction at temperatures above $80^{\circ} \mathrm{C}$. 
Alternatively, the parallel path to stable intermediates (formic acid and formaldehyde, reactions 5 and 6) and successive oxidation of these species (reactions 7 and 8) are perhaps so fast at these temperatures and potentials, that even though the pathways exist, we only observe the complete oxidation.

\section{Conclusions}

The dEIS technique was employed to study methanol oxidation reaction at elevated temperatures. It was found that the impedance behaviour of the system depends both on sweep rate and temperature. The variation with sweep rate shows that the technique detects non-steady surface states and that it is possible to access surface conditions not available with a steadystate technique. Increasing the sweep rate has the same effect on the impedance spectra as increasing the temperature: the regions with two adsorption relaxations in addition to the charge-transfer/double-layer relaxation disappear, reducing the number of adsorbed species from three to two. The third adsorbed species present, in addition to $\mathrm{CO}$ (ads) and $\mathrm{OH}(\mathrm{ads})$ or $\mathrm{CO}$ (ads) and $\mathrm{O}$ (ads), is likely associated with the parallel pathway. The disappearance of this species is interpreted as a decrease in the contribution by the parallel pathway at elevated temperatures.

\section{Acknowledgments}

The authors thank Natural Sciences and Engineering Research Council of Canada, University of Victoria, and Norwegian University of Science and Technology (NTNU) for financial support.

\section{References}

[1] Iwasita, T., Electrochim. Acta, 47, 3663 (2002).

[2] Lamy, C., Léger, J.-M., and Srinivasan, S., Modern Aspects of Electrochemistry, 53. Kluwer Academic/Plenum Publishers, New York (2001).

[3] Housmans, T. H. M., Hermse, C. G. M., and Koper, M. T. M., J. Electroanal. Chem., 607, 69 (2007).

[4] Jusys, Z. and Behm, R. J., In Fuel Cell Catalysis: A Surface Science Approach, Koper, M. T. M., editor, 411. Wiley \& Sons, Chichester (2009).

[5] Koper, M. T. M., Lai, S. C. S., and Herrero, E., In Fuel Cell Catalysis: A Surface Science Approach, Koper, M. T. M., editor. Wiley \& Sons, Chichester (2009).

[6] Wasmus, S. and Küver, A., J. Electroanal. Chem., 461, 14 (1999).

[7] Wang, H. and Baltruschat, H., J. Phys. Chem. C, 111, 7038 (2007). 
[8] Kardash, D. and Korzeniewski, C., Langmuir, 16, 8419 (2000).

[9] Chojak Halseid, M., Jusys, Z., and Behm, R. J., J. Phys. Chem., 114, 22573 (2010).

[10] Jusys, Z. and Behm, R. J., ECS Trans., 16, 1243 (2008).

[11] Otomo, J., Li, X., Kobayashi, T., Wen, C., Nagamoto, H., and Takahashi, H., J. Electroanal. Chem., 573, 99 (2004).

[12] Lee, J., Eickes, C., Eiswirth, M., and Ertl, G., Electrochim. Acta, 47, 2297 (2002).

[13] Melnick, R. E. and Palmore, G. T. R., J. Phys. Chem. B, 105, 1012 (2001).

[14] Hsing, I.-M., Wang, X., and Leng, Y.-J., J. Electrochem. Soc., 149, A615 (2002).

[15] Seland, F., Tunold, R., and Harrington, D. A., Electrochim. Acta, 51, 3827 (2006).

[16] Sacci, R. L. and Harrington, D. A., ECS Trans., 19, 31 (2009).

[17] Cohen, J. L., Volpe, D. J., and Abru na, H. D., Phys. Chem. Chem. Phys., 9, 49 (2007).

[18] Honma, I. and Toda, T., J. Electrochem. Soc., 150, A1689 (2003).

[19] Madden, T. H., Arvindan, N., and Stuve, E. M., J. Electrochem. Soc., 150, E1 (2003).

[20] Umeda, M., Sugii, H., and Uchida, I., J. Power Sources, 179, 489 (2008).

[21] Watanabe, M., Genlima, Y., and Turumi, K., J. Electrochem. Soc., 144, 423 (1997).

[22] Gasteiger, H. A., Marković, N., P. N. Ross, J., and Cairns, E. J., J. Electrochem. Soc., 141, 1795 (1994).

[23] Schell, M., J. Electroanal. Chem., 457, 221 (1998).

[24] Bevington, R., Data Reduction and Error Analysis for the Physical Sciences. McGraw-Hill, New York, (1969).

[25] Behm., R. J. and Jusys, Z., J. Power Sources, 154, 327 (2006).

[26] Seland, F., Tunold, R., and Harrington, D. A., Electrochim. Acta, 53, 6851 (2008).

[27] Seland, F., Harrington, D. A., and Tunold, R., Electrochimica Acta, 52, 773 (2006).

[28] Bokach, D., de la Fuente, J. L., Tsypkin, M., Ochal, P., Endsjø, I. C., Tunold, R., Sunde, S., and Seland, F., Fuel Cells, in press.

[29] Schmidt, T. J., Grgur, B. N., Markovic, N. M., and P. N. Ross, J., J. Electroanal. Chem., 500, 36 (2001).

[30] De Levie, R., J. Electroanal. Chem., 25, 257 (1970).

[31] Koper, M. T. M., Adv. Chem. Phys., 92, 161 (1996). 